\title{
Beyond the Status Quo: A Role for Beta Oscillations in Endogenous Content (Re)Activation
}

\author{
Bernhard Spitzer, ${ }^{1}$ and ${ }^{-}$Saskia Haegens ${ }^{2,3}$
}

DOI:http://dx.doi.org/10.1523/ENEURO.0170-17.2017

${ }^{1}$ Department of Experimental Psychology, University of Oxford, Oxford OX1 3UD, United Kingdom, ${ }^{2}$ Department of Neurological Surgery, Columbia University College of Physicians and Surgeons, New York, NY 10032, ${ }^{3}$ Centre for Cognitive Neuroimaging, Donders Institute for Brain, Cognition and Behaviour, Radboud University Nijmegen, Nijmegen 6500 HB, The Netherlands

\begin{abstract}
Among the rhythms of the brain, oscillations in the beta frequency range $(\sim 13-30 \mathrm{~Hz})$ have been considered the most enigmatic. Traditionally associated with sensorimotor functions, beta oscillations have recently become more broadly implicated in top-down processing, long-range communication, and preservation of the current brain state. Here, we extend and refine these views based on accumulating new findings of content-specific beta-synchronization during endogenous information processing in working memory (WM) and decision making. We characterize such contentspecific beta activity as short-lived, flexible network dynamics supporting the endogenous (re)activation of cortical representations. Specifically, we suggest that beta-mediated ensemble formation within and between cortical areas may awake, rather than merely preserve, an endogenous cognitive set in the service of current task demands. This proposal accommodates key aspects of content-specific beta modulations in monkeys and humans, integrates with timely computational models, and outlines a functional role for beta that fits its transient temporal characteristics.
\end{abstract}

Key words: beta rhythm; decision making; network interactions; neural oscillations; top-down control; working memory

\section{Significance Statement}

Brain oscillations at frequencies of $13-30 \mathrm{~Hz}$ (the beta rhythm) are traditionally associated with sensory and motor processing, but are increasingly implicated in various cognitive functions, such as working memory (WM) and decision making. Here, we review new evidence that beta activity in these domains can be content specific, that is, it can reflect the very information that is currently being processed. Going beyond previous accounts that link beta to maintenance of the current brain state, our review highlights the dynamic, often short-lived nature of beta modulations during endogenous information processing. We integrate these findings in a dynamic network view where beta-synchronization supports the internally driven (re)activation of neuronal ensembles to represent currently task-relevant contents.

\section{Introduction}

\section{Beta-band oscillations: beyond motor control}

Oscillations in the beta frequency range $(\sim 13-30 \mathrm{~Hz})$ have traditionally been associated with sensorimotor pro-

Received May 16, 2017; accepted July 17, 2017; First published July 21, 2017.

The authors declare no competing financial interests.

Author contributions: B.S. and S.H. wrote the paper.

This work was supported by Deutsche Forschungsgemeinschaft Grants SP cessing (Hari and Salmelin, 1997; Pfurtscheller and Lopes da Silva, 1999). During preparation and execution of movements, beta oscillations in sensorimotor cortex show marked power decreases (assumed to reflect local desynchronization), followed by a "rebound" of power

1510/1-1 and SP 1510/2-1 (to B.S.) and by the NWO Veni Grant 451-14-027 (to S.H.).

Acknowledgements: We thank Iske Bakker for assistance, Stephanie Jones and Mark Stokes for helpful feedback on this manuscript, and Nancy Kopell for insightful discussion. 


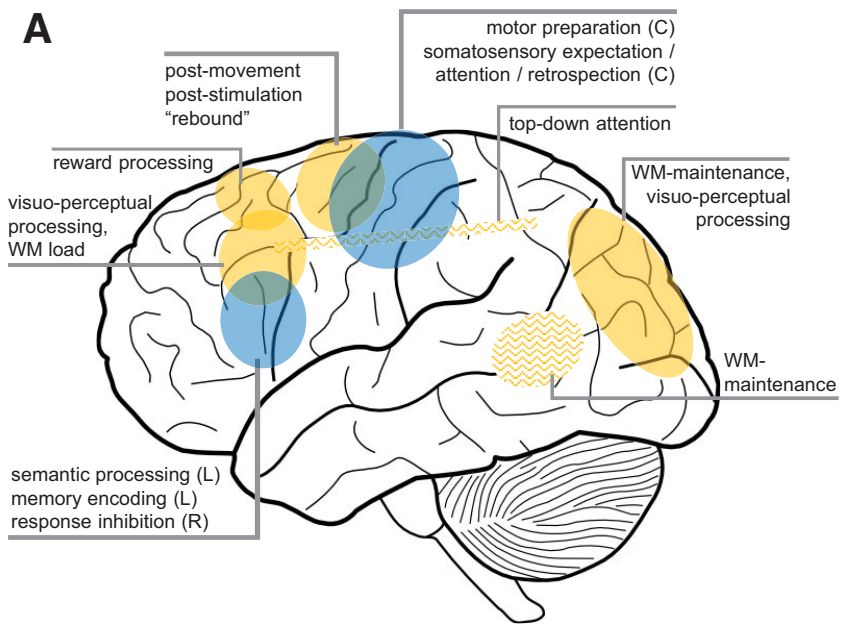

power change within-area

coherence between-area

coherence
B

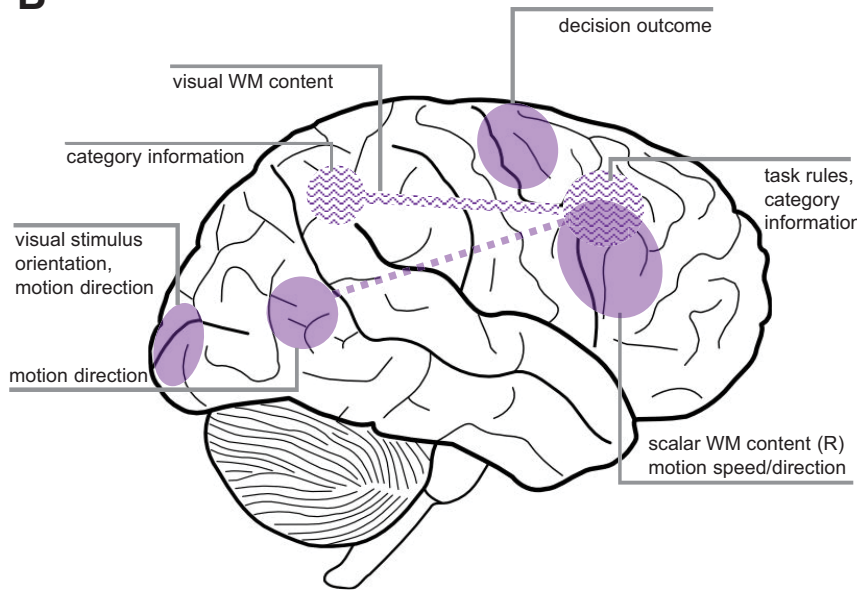

II $\| \pm=\begin{aligned} & \text { spike-field } \\ & \text { coherence }\end{aligned}$ decrease

content-specific

modulation

Figure 1. Beyond motor control. Schematic overview of oscillatory beta-band effects across cortex. $\boldsymbol{A}$, Overall beta activity changes (in-/decreases) associated with different cognitive functions (NB, nonexhaustive schematic). $\boldsymbol{B}$, Content-specific modulations of beta-band activity; see text for details. For convenience, findings from human- and nonhuman primate studies are illustrated on a common template. Unless specified (L, left; R, right; C, contralateral), effects were not systematically lateralized.

(i.e., synchronization) after movement (Kilavik et al., 2013). A similar sequence of beta power changes is observed in somatosensation, with desynchronization in anticipation of and during stimulation, followed by (re)synchronization after stimulus offset (Bauer et al., 2006; Spitzer et al., 2010; Van Ede et al., 2010). The dynamics of beta activity in sensorimotor cortex often resemble and/or parallel modulations of alpha band activity $(\sim 8-12 \mathrm{~Hz})$, in that power decreases with active engagement, for instance during spatial attention (Bauer et al., 2006; Schubert et al., 2009; Jones et al., 2010; Van Ede et al., 2011; but see Haegens et al., 2012). However, whereas alpha oscillations are widely linked to the inhibition of task-irrelevant areas (Klimesch et al., 2007; Jensen and Mazaheri, 2010; Haegens et al., 2011a), the precise functional role of sensorimotor beta-synchrony remains unclear. Initially believed to reflect cortical idling (Pfurtscheller et al., 1996; Neuper and Pfurtscheller, 2001), more recent views suggest a role in maintaining the current sensorimotor set, or "status quo" (Engel and Fries, 2010; cf. Jenkinson and Brown, 2011).

Beyond its established role as a sensorimotor rhythm, beta activity has been observed in various different cortical areas and is increasingly implicated in a wider range of cognitive functions (Engel and Fries, 2010). Modulations of beta oscillatory activity in nonsomatomotor areas (e.g.,

Correspondence should be addressed to either of the following: Bernhard Spitzer, Department of Experimental Psychology, University of Oxford, Oxford OX1 3UD, United Kingdom, E-mail: bernardodispitz@gmail.com; or Saskia Haegens, Department of Neurological Surgery, Columbia University College of Physicians and Surgeons, New York, NY 10032, E-mail: shaegens@gmail.com. DOI:http://dx.doi.org/10.1523/ENEURO.0170-17.2017

Copyright (C) 2017 Spitzer and Haegens

This is an open-access article distributed under the terms of the Creative Commons Attribution 4.0 International license, which permits unrestricted use, distribution and reproduction in any medium provided that the original work is properly attributed. frontal, parietal, visual; Fig. $1 A$ ) have been associated with visual perception (Donner et al., 2007; Piantoni et al., 2010; Kloosterman et al., 2015), language processing (for review, see Weiss and Mueller, 2012), working memory (WM; Tallon-Baudry et al., 1998; Deiber et al., 2007; Axmacher et al., 2008; Siegel et al., 2009), long-term memory encoding and retrieval (Sederberg et al., 2006; Hanslmayr et al., 2009; Spitzer et al., 2009; for review, see Hanslmayr et al., 2016), decision making (Pesaran et al., 2008; Wimmer et al., 2016; Wong et al., 2016), response inhibition (Jha et al., 2015), and reward processing (for review, see Marco-Pallarés et al., 2015). In some of these contexts, beta-band modulations occur in a relatively low frequency band ("lower" beta, 13-20 Hz) and in tandem with alpha (Hanslmayr et al., 2009). In other cases, betaband rhythms of varying frequencies (including "upper" beta, $\sim 20-30 \mathrm{~Hz}$ ) behave in ways more similar to gamma activity $(>30 \mathrm{~Hz})$ and increase, rather than decrease, with task-related engagement (Tallon-Baudry et al., 1998; Marco-Pallarés et al., 2015; Kornblith et al., 2016).

While a unifying theoretical account of cortical beta oscillations is currently lacking, some mechanistic aspects have been tentatively identified. In particular, beta oscillations are mostly associated with endogenous, topdown-controlled processing (Buschman and Miller, 2007; for review, see Engel and Fries, 2010; Wang, 2010; Fries, 2015). Furthermore, in line with a "communication through coherence" view (Fries, 2005, 2015), oscillations in the beta frequency range are assumed to facilitate longrange interactions on a cortical network level (Kopell et al., 2000; Varela et al., 2001; Benchenane et al., 2011; Kilavik et al., 2013). Both these aspects have been integrated in a predictive coding framework, where gamma-synchronization serves feedforward (bottom-up) communication, whereas beta-synchronization affords feedback commu- 
nication of top-down predictions (Arnal and Giraud, 2012; Bastos et al., 2012; Bastos et al., 2015; Michalareas et al., 2016). One of the many persistent puzzles regarding beta, however, remains its unclear relation to neuronal activity as measured in spike firing rates and/or blood-oxygenlevel dependent (BOLD) signals. Whereas oscillations in other frequency bands are known to correlate either positively (e.g., gamma) or negatively (e.g., alpha) with these activity measures, findings for beta have been mixed (e.g., Michels et al., 2010; Hanslmayr et al., 2011), with some studies showing no correlation at all (e.g., Whittingstall and Logothetis, 2009; Rule et al., 2017).

Perhaps surprisingly in light of the above, an increasing number of findings indicate that in some task contexts, beta oscillatory activity can be content specific, that is, it can reflect the very information that is currently being processed (Fig. 1B). Across human and monkey species, content-specific beta activity was found to carry information about internalized task rules (Buschman et al., 2012), stimulus categories (Antzoulatos and Miller, 2014, 2016; Stanley et al., 2016), scalar magnitudes (Spitzer et al., 2010; Spitzer and Blankenburg, 2011; Spitzer et al., 2014a) and other stimulus properties (Salazar et al., 2012; Mendoza-Halliday et al., 2014; Lewis et al., 2016; Wimmer et al., 2016), as well as subjective comparison outcomes (Haegens et al., 2011b; Herding et al., 2016). Such content-specific beta activity has in particular been observed during endogenous information processing in WM and decision making. Before considering these two domains in greater detail, we briefly discuss by which neurophysiological mechanisms beta oscillations might be generated.

\section{Generation of cortical beta oscillations}

Two main views exist in the literature, suggesting that (1) beta is generated in cortex (Jensen et al., 2005; Roopun et al., 2006; Kramer et al., 2008; Kopell et al., 2011; Sherman et al., 2016), or (2) that beta is generated in the basal ganglia and propagated to cortex via the thalamus (Holgado et al., 2010; McCarthy et al., 2011). Within the view of cortically generated beta, one class of models suggests that beta is generated by local spiking interactions among cells, either consisting of pyramidal cellinterneuron loops (Jensen et al., 2005; Kramer et al., 2008; Kopell et al., 2011; Lee et al., 2013) or layer 5 pyramidal cells coupled via gap junctions (Roopun et al., 2006). A more recent proposal (Sherman et al., 2016) suggests an intermediate model, with beta being generated in cortex but depending on a (laminae-specific) exogenous drive originating from subcortical and/or cortical influences (see also Schmiedt et al., 2014, suggesting cortical beta generation driven by thalamic and/or top-down cortical inputs).

Based on local generator models, it has been suggested that beta is ideally suited for flexibly and dynamically forming cell assemblies (Roopun et al., 2008; Kopell et al., 2011), and for long-distance inter-area communication (Kopell et al., 2000). These models rely on local spiking interactions between excitatory and inhibitory neurons, and on intrinsic currents of the underlying pyra- midal cells (e.g., h-currents or m-currents, determining the cell's rebound after hyperpolarization), defining the time constants for spike firing, thereby contributing to beta rhythmogenesis (Roopun et al., 2008; Kopell et al., 2011). Kopell et al. (2011) suggest that beta-synchronized cell assemblies are robust as they are self-sustaining after a long, decaying excitatory input [contrary to pyramidalinterneuron gamma (PING)-based networks, which need ongoing input; PING, a model of local circuit gamma generation], and can concurrently exist with other cell assemblies (again, contrary to PING assemblies which compete with one another as they rely on the same inhibitory interneurons). The sustained nature of these cell assemblies, spiking at a low beta rate $(\sim 15 \mathrm{~Hz})$, would allow maintaining of neuronal activity patterns, i.e., a mechanism for WM, and the linking of past and present inputs.

More recently, Sherman et al. (2016) proposed a model building on prior work (Jones et al., 2007; Jones et al., 2009; Sacchet et al., 2015), where cortical beta is generated in the apical dendrites of large populations of spatially aligned pyramidal neurons, which span several layers. Specifically, this model produces transient beta activity $(<150 \mathrm{~ms})$ by the integration of simultaneous (subthreshold) excitatory drives to the proximal (closer to the soma) and distal apical dendrites of pyramidal cells located in supragranular (layers 2/3) and infragranular layers (layer 5 ). The weaker proximal drive (of $\sim 100$-ms duration) arrives via granular (layer 4), the stronger distal drive $(\sim 50 \mathrm{~ms})$ via the supragranular layers, with both extrinsic drives arising from thalamic or potentially higherorder cortical areas. The model accurately generates beta "burst" events ( $<150 \mathrm{~ms})$, with a nonsinusoidal wave form as observed in spontaneous human, monkey and rodent recordings (Sherman et al., 2016). Moreover, within this framework, when both drives arrive nearly synchronously at a $10-\mathrm{Hz}$ rate, a sustained beta rhythm can be produced. Note that a beta-rate input is neither required nor sufficient for this model to produce realistic beta events (contrary to models that assume generators in the basal ganglia), nor do individual cells fire at a beta rate (in contrast with other local generator models). Rather, beta oscillatory activity arises from net subthreshold dendritic fluctuations, relying on integration of feedforward (to granular layer) and, critically, feedback inputs (to supragranular layers).

\section{Beta-band oscillations in WM}

Numerous studies have reported beta power increases, concomitant with modulations in other frequency bands, during WM maintenance of visual (Tallon-Baudry et al., 1998; Liebe et al., 2012; Lara and Wallis, 2014; Wimmer et al., 2016), verbal (Deiber et al., 2007), or temporal information (Chen and Huang, 2016). Such effects occur in frontal, parietal, and/or temporal areas, and can vary with WM load, i.e., the amount of to-be-maintained information (Deiber et al., 2007; Honkanen et al., 2015; Chen and Huang, 2016; see also Palva et al., 2011; Kornblith et al., 2016). In addition, several studies have shown that WM demands can alter the degree to which beta oscilla- 
tions are phase synchronized, both within and between cortical areas (Tallon-Baudry et al., 2001; Babiloni et al., 2004; Tallon-Baudry et al., 2004; Axmacher et al., 2008; Salazar et al., 2012; Dotson et al., 2014).

Findings of enhanced beta activity in WM tasks appear consistent with a role in actively maintaining the current cognitive set, i.e., the status quo (Engel and Fries, 2010). However, overall changes of oscillatory activity during WM processing can depend on various task factors and are also often found in frequency bands other than beta, especially theta $(4-7 \mathrm{~Hz})$, alpha, and gamma (for review, see Fell and Axmacher, 2011; Roux and Uhlhaas, 2014). While overall activity changes may reflect involvement in WM, more direct insights into the mechanisms of WM storage can be gained from delay activity that reflects the current memory content, in terms of the task-relevant stimulus information that is to-be-maintained on a given trial (Christophel et al., 2017). Such content-specific delay activity has traditionally been observed in persistent neuronal spiking (e.g., Kubota et al., 1974; Miller et al., 1996), local gammaband activity (Pesaran et al., 2002), as well as BOLD activity patterns (Harrison and Tong, 2009). However, a growing body of recent literature indicates that WM contents can also be reflected in oscillatory brain signals, particularly in the beta frequency range (Spitzer et al., 2010; Spitzer and Blankenburg, 2011; Salazar et al., 2012; Mendoza-Halliday et al., 2014; Antzoulatos and Miller, 2016; Rose et al., 2016; Wimmer et al., 2016).

\section{Content-specific modulations in scalar WM}

One line of evidence for content-specific delay activity in the beta-band comes from studies of WM for scalar magnitudes, such as the speed, intensity, or duration of a stimulus. The neural basis of scalar information processing has been studied in great detail in a classic somatosensory task (Mountcastle et al., 1967; Romo and de Lafuente, 2013), where monkeys were trained to memorize the frequency of a brief tactile vibration (f1) for delayed comparison against a second vibration (f2; Fig. $2 A$, top). As a seminal finding in this task, the trial-specific $f 1$ frequency is encoded parametrically, i.e., in a monotonically graded fashion, in neuronal firing rates throughout the cortical processing hierarchy (Romo and de Lafuente, 2013). During the WM delay after $f 1$, such parametric coding prevails in prefrontal cortex (PFC) and premotor cortex, with different cell populations either positively or negatively tuned to the frequency of $\mathrm{f1}$ (Romo et al., 1999; Hernández et al., 2002; Barak et al., 2010). In subsequent human EEG experiments, similar effects were observed in prefrontal beta activity, with parametric modulations of oscillatory power as a function of $\mathrm{f} 1$ frequency (Spitzer et al., 2010; Spitzer and Blankenburg, 2011; Ludwig et al., 2016). Further studies showed that such beta power modulations are not specific to vibrotactile frequency information, but can also be observed for other analog continua, like stimulus intensity, motion speed, or approximate number (Spitzer et al., 2014a,b; Wimmer et al., 2016). A general picture emerging from this line of work is that at least some of the computations underlying scalar WM are supramodal (Spitzer and Blankenburg, 2012; Vergara et al., 2016; see also Nieder, 2012), potentially reflecting high-level abstractions of the task-relevant magnitude, rather than concrete sensory information (Spitzer et al., 2014a,b; see also Christophel et al., 2017).

\section{Content-specific (de)synchronization within and across areas}

The modulations of beta activity in scalar WM tasks were observed in power measures, which are thought to reflect the local (de)synchronization of neuronal ensembles within a brain area (Pfurtscheller and Lopes da Silva, 1999). However, using more complex stimuli, content-specific WM activity in the beta-band has also been observed on a largerscale cortical network level. For instance, in simultaneous recordings from prefrontal and parietal cortex in behaving monkeys, information about memorized visual objects could be decoded not only from sustained spiking in either region, but also from the level of beta-band synchronization between regions (Salazar et al., 2012) (Fig. 2E). Similarly, betasynchronization of prefrontal networks was found to reflect currently relevant task-rules (Buschman et al., 2012) (Fig. 2F, 4C) and stimulus categories (Antzoulatos and Miller, 2014, 2016; Stanley et al., 2016). In another recent study, memory-coding neurons in monkey lateral PFC were found to be synchronized via beta oscillations to motionsensitive area MT, in which the memorized motion information was also reflected in local field potential (LFP) power but not in spiking activity (Mendoza-Halliday et al., 2014). The latter findings were interpreted as evidence for top-down signaling from PFC to lower-level visual areas, in line with the emerging notion of beta oscillations as a communication channel for top-down and feedback information across cortex (Buschman and Miller, 2007; Bastos et al., 2015).

\section{A role in (re)activating WM content}

Several lines of evidence suggest that content-specific beta oscillations do not reflect a persistent memory trace per se, but rather, a class of endogenous processes that are auxiliary to WM processing. For instance, contentdependent beta activity is typically not sustained throughout entire memory delays (of several seconds), but relatively short lived, often lasting only several hundreds of milliseconds (Spitzer and Blankenburg, 2011; Salazar et al., 2012). Furthermore, unlike WM codes in neuronal spiking (Romo et al., 1999; Barak et al., 2010), prefrontal beta modulations are usually absent during stimulation, and seem to emerge only at particular times during WM retention (Fig. 2A-D). More specifically, in standard delay tasks, beta modulations are mostly found late in the delay (Spitzer et al., 2010; Salazar et al., 2012; Spitzer and Blankenburg, 2012; Wimmer et al., 2016), when WM information might be endogenously (re)activated or "refreshed" (Johnson, 1992) in preparation for the imminent comparison task (Spitzer et al., 2010; Myers et al., 2015; Wimmer et al., 2016). In contrast, when participants were explicitly (retro)-cued to update WM with one of two previously presented stimuli for further maintenance, prefrontal beta was modulated early after the cue, and therein selectively reflected the cued stimulus information 
A

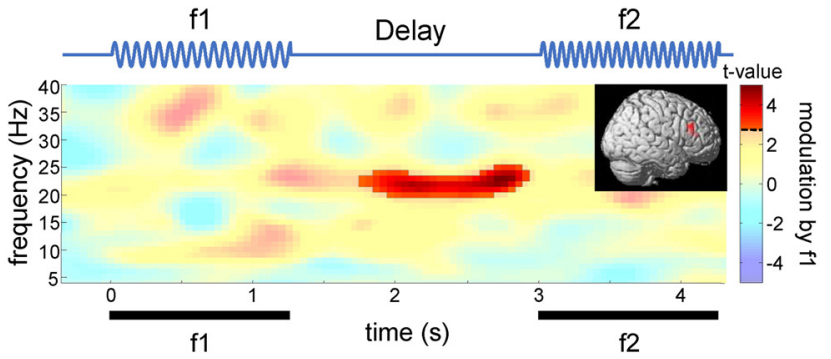

B
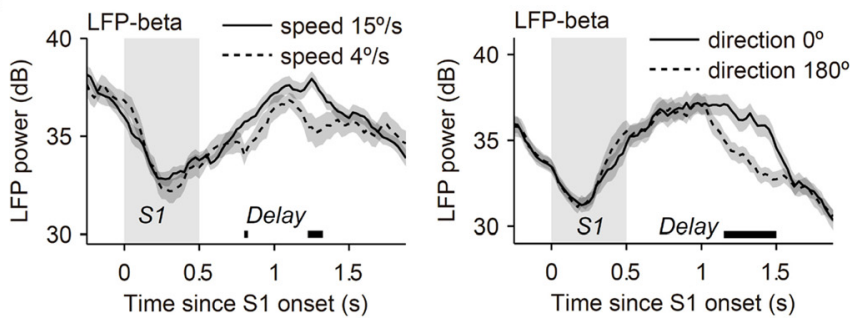

E
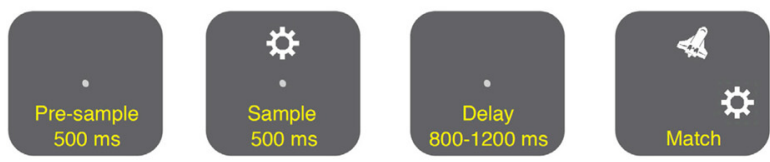

Identity of the sample object
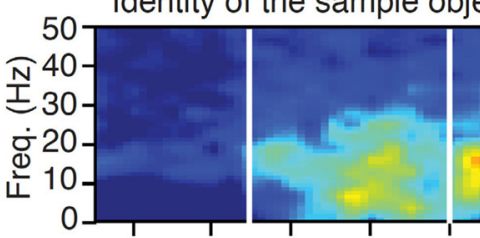

CSI (bits)

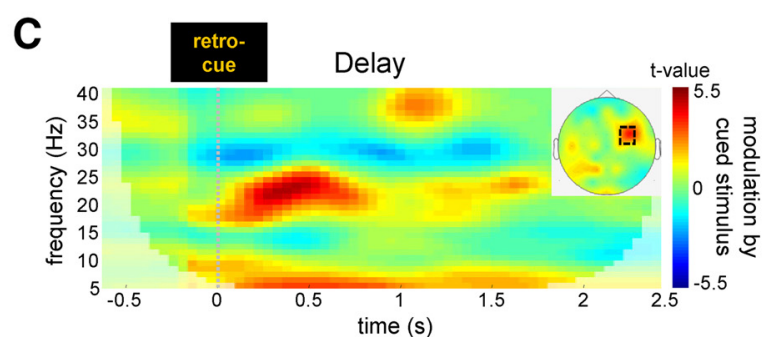

D

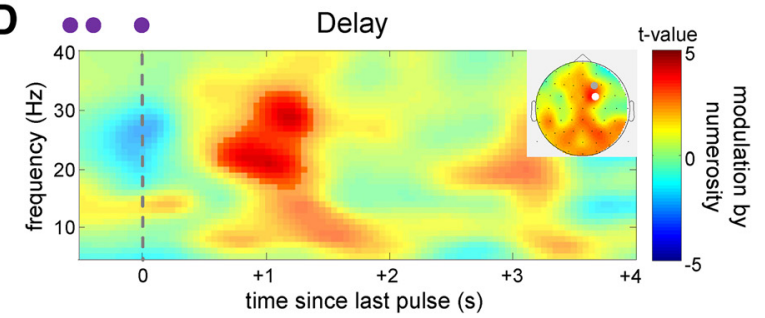

F

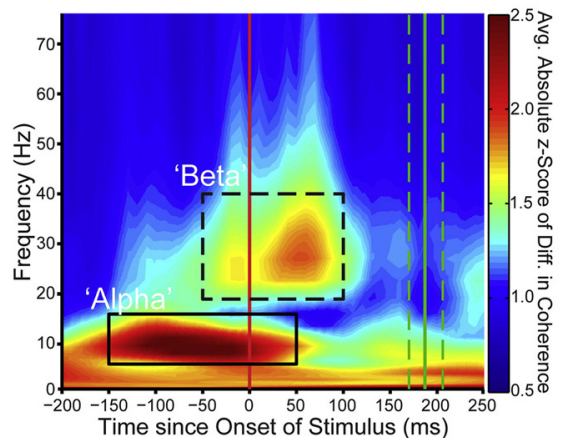

Figure 2. Content-specific beta activity during WM processing. $\boldsymbol{A}$, During WM maintenance of vibrotactile frequency information, prefrontal EEG beta power is parametrically modulated by the frequency of the to-be-maintained stimulus (f1). Adapted with permission from Spitzer et al. (2010). B , Similar beta power modulations were found in LFP recordings in monkey PFC during WM maintenance of visual motion information. Adapted with permission from Wimmer et al. (2016). Note that in standard delay tasks, beta modulations occurred mostly late in the WM delay period. $\boldsymbol{C}$, In contrast, when participants were retro-cued to focus on a given WM content for further maintenance, beta was modulated early after the cue. Adapted with permission from Spitzer and Blankenburg (2011). D. Similar transient modulations were observed during WM processing of the approximate number of previously presented inputs (three to eight pulses in rapid sequence, illustrated in purple). Adapted with permission from Spitzer et al. (2014a). $\boldsymbol{E}$, Content-specific fronto-parietal beta-synchronization during WM maintenance of visual object information in monkeys. As in $\boldsymbol{A}-\boldsymbol{D}$, these effects were absent during stimulus encoding. Adapted with permission from Salazar et al. (2012). Reprinted with permission from AAAS. $\boldsymbol{F}$, Rule-dependent beta-synchronization in monkey PFC at the time of the to-beevaluated stimulus (see also Fig. 4C). Adapted with permission from Buschman et al. (2012). Reprinted with permission from Elsevier.

(Spitzer and Blankenburg, 2011; Spitzer et al., 2014b). Similarly, in tasks where the scalar magnitude of a stimulus could only be assessed after integration over time (e.g., the number of pulses in a sequence), beta modulations occurred promptly after the accumulation period, as if the task-relevant scalar was "activated" in WM as soon as it was internally computed (Spitzer et al., 2014a,b). Taken together, rather than a substrate of persistent memory storage per se, prefrontal beta modulations seem to reflect the momentary updating, or (re)activation, of WM content in the service of the task at hand.

To our knowledge, content-specific beta activity in WM has thus far only been observed during single-item maintenance (Salazar et al., 2012; Dotson et al., 2014; Mendoza-Halliday et al., 2014), and several findings suggest that the capacity of beta-associated WM updating might be limited to a single piece of information in the current focus of attention (Spitzer and Blankenburg, 2011; Spitzer et al., 2014b; Antzoulatos and Miller, 2016; Wimmer et al., 2016; cf. Oberauer, 2002). However, one recent study showed that an additional, currently unattended memory item can be pushed into an active WM state by transcranial magnetic stimulation (TMS) of WM-coding areas (Rose et al., 2016). Interestingly, whereas the currently attended memory information could be decoded from various EEG frequency bands, the TMS-induced reactivation of the unattended memory item was exclusively evident in content-specific beta activity. In other words, beta activity specifically marked the transition of "latent" WM contents (see below; Mongillo et al., 2008; Stokes, 2015) into an active memory, consistent with a 
role of beta in updating, or reactivating, information in the current focus of WM.

\section{Neurocomputational perspectives on beta oscillations in WM}

A role of beta oscillations in WM has also been put forward in computational modeling work (Kopell et al., 2011; Lundqvist et al., 2011; Dipoppa and Gutkin, 2013). Simulations by Kopell et al. (2011), for instance, showed beta oscillations to be uniquely suited to form and coordinate cell assemblies for sustained stimulus processing in the absence of further input, eventually permitting the coexistence of past and present stimulus information in the same network. In this view, beta rhythms may scaffold functional assemblies for active WM processing. Another line of modeling studies, with a focus on multi-item WM, suggests a sequential replay of individual WM items (see also Lisman and Jensen, 2013), in terms of alternations between "ground" and "active" states (see below), where the former is dominated by alpha/beta and the latter by gamma (Lundqvist et al., 2010; Lundqvist et al., 2011). Corroborating this idea, Lundqvist et al. (2016) reported a dissociation between beta and gamma during multi-item WM in monkey PFC, where gamma bursts were associated with stimulus encoding and decoding in spikes, whereas beta bursts prevailed during memory maintenance. However, it was not analyzed whether beta and/or gamma bursts themselves carried information about the WM contents, leaving the question of content-specific beta activity in multi-item WM to future research (but see Siegel et al., 2009, for a potential role of beta phase in multi-item WM).

\section{Beta-band oscillations in decision making}

Given the well-documented involvement of beta-band oscillations in movement preparation (Murthy and Fetz, 1992; Sanes and Donoghue, 1993; Crone et al., 1998; Pfurtscheller and Lopes da Silva, 1999), it seems not surprising that sensorimotor beta effects are routinely observed in decision-making tasks where choices are to be communicated via a motor response (Kaiser et al., 2007; Zhang et al., 2008; Bidet-Caulet et al., 2012). During perceptual discrimination of auditory stimuli, for instance, the latency of preparatory beta power modulation was found to mimic response time differences across varying levels of task difficulty (Kaiser et al., 2007). Such effects typically manifest as sensorimotor power decreases contralateral to the to-be-moved limb, and are commonly assessed using lateralization indices (e.g., contrasting left- vs. right-hemispheric activity associated with right/ left hand choices; Donner et al., 2009; Gould et al., 2012; Wyart et al., 2012). A traditional view is that beta oscillations in decision-making reflect motor preparation only, i.e., a serial processing view where the effector-specific motor plan is the final step, after higher-order areas have reached a decision based on sensory input. However, as will be outlined below, accruing evidence points to a more direct involvement of beta oscillations in decision formation, which may or may not be linked to a specific motor plan.

\section{Dynamic accumulative updating}

Several recent studies suggest that lateralized beta activity during decision-making tasks may not only reflect terminal movement preparation, but a dynamic process of accumulatively updating a motor plan as a decision evolves (Donner et al., 2009; Gould et al., 2012; O'Connell et al., 2012; Wyart et al., 2012; Kubanek et al., 2013; Wyart et al., 2015). For instance, analyzing human MEG activity in a visual motion-detection task, Donner et al. (2009) reported a slowly evolving, gradual beta power lateralization in (pre)motor cortex that tracked the current state of evidence accumulation, as inferred from the temporal integral of gamma activity in motion-sensitive area MT (Fig. 3A). Similar observations were made in human EEG studies where participants integrated sequential samples of decision information over extended periods of time (Gould et al., 2012; Wyart et al., 2012; Kubanek et al., 2013; Wyart et al., 2015). In these studies, sensorimotor beta was found to reflect the integral of accumulated decision information in the form of a gradual response preparation signal, downstream to the encoding of sample-level decision information in parietal EEG signals (Gould et al., 2012; Wyart et al., 2012; Kubanek et al., 2013).

Together, these studies support a role for beta in dynamic updating of the decision outcome as mapped onto a motor response. However, a key point in the above studies is that they a priori operationalized beta activity as a response-related signal. More specifically, they used a fixed mapping between decision outcomes and motor responses (usually left/right hand action), and assessed sensorimotor beta activity in terms of lateralization indices, relying on the contra-lateralized nature of sensorimotor activity. Critically, this approach disregards choice-related activity that might occur independent of the associated left/right response mapping. In fact, when the fixed link between decision outcomes and left/right effectors is removed, the effects in sensorimotor beta lateralization typically disappear (O'Connell et al., 2012; Twomey et al., 2016).

\section{A content-specific decision signal?}

Several recent studies go beyond this approach, and demonstrate a role for beta oscillations in perceptual decision tasks that appears independent of motorresponse mapping (Haegens et al., 2011b; Herding et al., 2016; Stanley et al., 2016; Wimmer et al., 2016). Haegens et al. (2011b) used a variant of the somatosensory frequency discrimination task described earlier (Mountcastle et al., 1967; Romo and de Lafuente, 2013). As outlined above, during the retention period of such tasks, the first stimulus frequency ( $\mathrm{f} 1)$ is reflected parametrically in (pre)frontal areas, both in terms of single-cell firing rates (Romo et al., 1999; Barak et al., 2010; Vergara et al., 2016) and in upper beta activity (Spitzer et al., 2010). Notably, during the ensuing decision period (i.e., after $\mathrm{f} 2$ is presented), Haegens et al. (2011b) found that the level of beta power in monkey sensorimotor cortex (including somatosensory, premotor and motor areas) signaled the categorical outcome of the f1-f2 comparison (i.e., "f2 > f1" or 
A

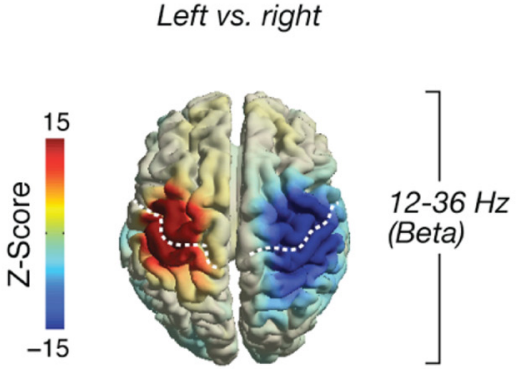

B

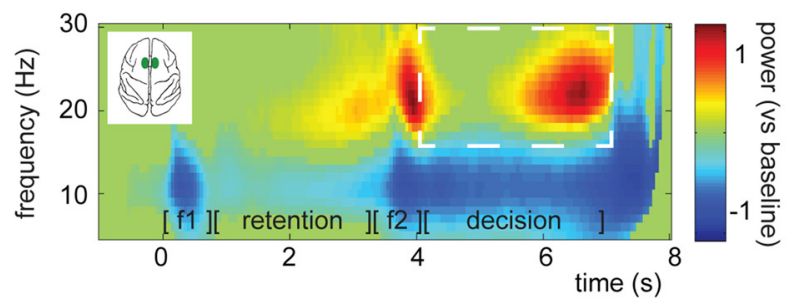

C
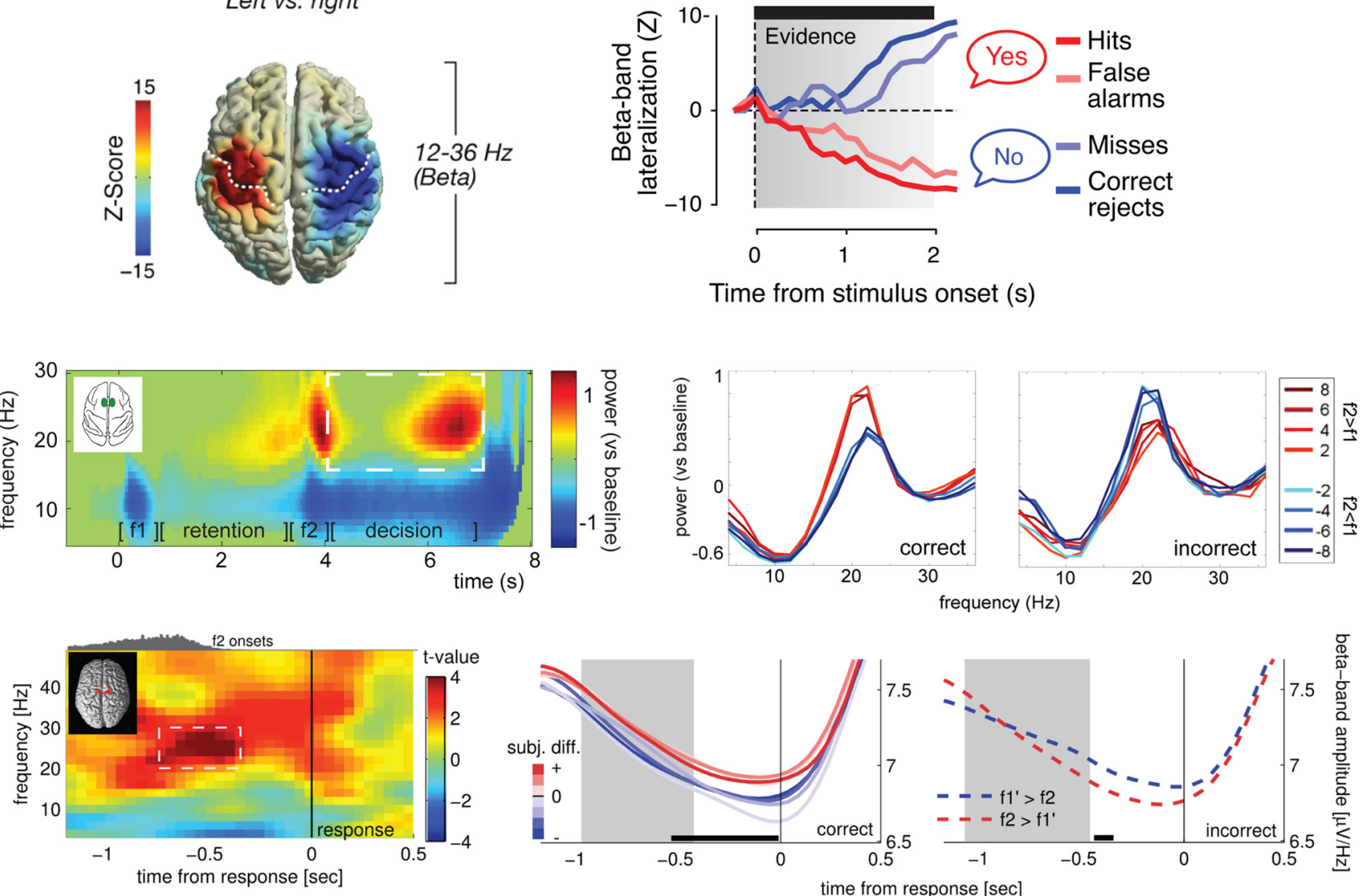

Time from stimulus onset (s)

Figure 3. Content-specific beta activity during decision making. $\boldsymbol{A}$, Source reconstruction showing lateralized, effector-selective beta activity (left- vs right-hand response) before button press, in human subjects performing a visual motion detection task (left panel). Time courses of lateralized beta activity in motor cortex indicate accumulative updating of the motor plan as a decision evolves (right panel). Adapted with permission from Donner et al. (2009). Reprinted with permission from Elsevier. B, Beta power modulation in monkey medial premotor cortex before motor response in vibrotactile discrimination task reflects binary decision outcome, also on error trials. Spectra on the right are averaged over the time window indicated by dashed box in the left panel, per stimulus class (sorted by f2-f1 difference), for correct and incorrect trials separately. Adapted with permission from Haegens et al. (2011b). C, Remarkably similar observation as in $\boldsymbol{B}$, in human EEG recordings using the same paradigm. Adapted with permission from Herding et al. (2016). (C) 2016 by the Massachusetts Institute of Technology, published by the MIT Press.

"f1 $<\mathrm{f} 2$ "). This effect proved independent of the absolute frequencies of $\mathrm{f} 1$ and $\mathrm{f} 2$ (or their exact numerical difference) and reflected the monkey's categorical choices even on error trials (Fig. 3B). Importantly, this choicerelated beta activity was not merely related to motor planning, as all choices were reported with the left hand, and the effect disappeared in a control condition in which the same motor response but no f1-f2 comparison was required. These findings complement previous reports on spike firing rate modulation in the same paradigm: during the comparison period, firing rates of sensorimotor and prefrontal cells gradually reflected a categorical response, corresponding to the decision outcome (Hernández et al., 2002; Romo et al., 2002; Hernández et al., 2010). Therein, similar to the "parametric" WM ensembles described earlier (Romo et al., 1999), decision-coding cells fall into two complementary classes, with one group of cells positively tuned (i.e., increasing its firing) to the $\mathrm{f} 2>\mathrm{f} 1$ choice and another negatively tuned (Hernández et al., 2002).
A beta-band effect replicating and extending the monkey findings by Haegens et al. (2011b) was recently observed in human EEG recordings (Herding et al., 2016). Here too, during vibrotactile frequency discrimination, the level of nonlateralized beta power in premotor areas was modulated according to participants' decision outcomes (f2 $>\mathrm{f} 1$ or $\mathrm{f} 2<\mathrm{f} 1$ ) in a categorical fashion (Fig. $3 C$ ). Again, this effect reflected subjective choices, including errors, as inferred from Bayesian modeling of $\mathrm{f1}$ - $\mathrm{f} 2$ choice behavior. Furthermore, capitalizing on a larger subject sample, this effect was found to be invariant across motor response mappings: even when the response scheme (index or middle finger of the right hand) was flipped (across participants), the beta modulations remained unchanged (Herding et al., 2016). In a follow-up study, virtually identical beta patterns were observed when saccades rather than button presses were used to communicate the decision. Now decision-selective beta activity was localized to more lateral premotor areas (including the frontal eye fields), suggesting a degree of 
effector specificity in terms of areas involved, but with a consistent role for beta (Herding et al., 2017).

Combined, these studies suggest that in scalar comparison tasks, sensorimotor beta oscillations can reflect the categorical, potentially abstract content of a decision, even independent of a concrete motor plan. One possibility is that such nonlateralized, content-dependent beta activity relates to the endogenous activation of categorical, conceptual information before local translation into an effector-specific response. This interpretation is in line with a recent study recording LFPs in lateral PFC of macaques performing a visual categorization task, which reported different patterns of beta coherence for different categories of morphed stimuli (ranging for instance from cat to dog), "as if low-beta coherence was helping to form the neural ensembles that represented the categories" (Stanley et al., 2016). In further support of this view, when macaques had to judge random-dot motion stimuli, beta activity in lateral PFC signaled the categorical decision outcome (here, "same" or "different"), with beta modulation in different recording sites corresponding to the different outcomes (Wimmer et al., 2016). As for the somatosensory studies discussed above, this observation complemented findings from single unit spike recordings in the same paradigm (Hussar and Pasternak, 2012): different cells increased their firing rate either for same or for different choices. Thus, there appear to be parallels between modulations of local beta activity and single unit firing rates, in that both signal the emergence of a categorical decision outcome.

\section{Decision circuits}

The role of beta oscillations in decision making might be extended to include long-range interactions, again in line with WM findings discussed earlier. The decision effects observed by Haegens et al. (2011b), for instance, included a distributed network of somatosensory and (pre)motor areas. More direct support for a role in network-level processing comes from a reach-planning study, demonstrating higher beta-band spike-field coherence (SFC; the synchronization of spikes to oscillatory phase) between premotor cortex and the parietal reach region when monkeys were freely making choices as compared to instructed choices (Pesaran et al., 2008). The authors proposed that here, beta coherence reflected a decision circuit between frontal and parietal cortex, which was more activated under free choice conditions. Similarly, beta-band SFC in posterior parietal cortex reflected decisions in a reward-guided choice task (Hawellek et al., 2016). In this study, information about movement choice in firing rates was quantified and related to the phase of beta and gamma oscillations. While for gamma, peak firing rate and maximum information content coincided, for beta the highest spike count preceded maximum information. These differences in temporal alignment were linked to the idea that gamma reflects local, bottom-up processing, while beta links distributed ensembles for computations on a larger scale. Further evidence for beta facilitating long-range communication was obtained in a recent auditory perceptual decision-making study, in which large-scale network dynamics in the beta-band predicted decision speed (Alavash et al., 2017).

To summarize, a growing body of evidence suggests that content-specific beta oscillations can signal the endogenous activation of a categorical decision outcome before translation into a concrete motor response. Several studies show that such contentspecific decision activity in the beta-band can be observed beyond sensorimotor regions, both within and between distributed cortical areas.

\section{A role for beta oscillations in endogenous content (re)activation}

In the previous sections, we have discussed research in the domains of WM and decision making, showing that beta activity can be modulated in a content-specific manner. Here, we outline a framework for beta oscillations in endogenous (re)activation of cortical content representations (Fig. 4A). We presume that active cortical representations of task-relevant information are reflected in the (spiking) activity of content-specific neuronal ensembles (Fig. 4A, first panel). We further assume that in the absence of stimulation or endogenous prioritization, representations of task-related information can persist without sustained ensemble spiking, for instance, in patterns of synaptic weights (Jonides et al., 2008). Such dormant, or latent memory representations (Fig. 4A, second panel) may for instance be characterized by short-term synaptic facilitation (Mongillo et al., 2008; Stokes, 2015) for just presented stimuli, and/or by long-term synaptic potentiation (Hebb, 1949) for overlearned (e.g., abstract/categorical) contents. A general assumption in this framework is that latent memory information can be endogenously restored into an active (i.e., spiking) cortical representation (Fig. 4A, last panel), for instance by top-down attentional prioritization (Warden and Miller, 2007; Jonides et al., 2008; Jacob and Nieder, 2014; Watanabe and Funahashi, 2014; Sprague et al., 2016). The mechanisms by which such endogenous (re)activation might occur, however, have thus far remained unclear. Here, based on the accumulating evidence reviewed above, we propose that this role is filled by content-specific beta-band activity. More specifically, we suggest that episodes of contentspecific beta-synchronization support the endogenous transition from latent to active cortical representations (Fig. $4 A$, third panel), in the service of current task demands.

Oscillatory synchronization is associated with fluctuations in local network excitability (Bishop, 1932), and faster rhythms $(>15 \mathrm{~Hz})$ in particular are proposed to support flexible information routing by providing windows of efficient inter-areal communication (Fries, 2015; Palmigiano et al., 2017). Oscillations in the beta-band seem particularly well suited to fill these roles during endogenously driven information processing, given (1) their association with top-down processing (Engel and Fries, 2010; Wang, 2010) and (2) long-range communication (Kopell et al., 2000; Varela et al., 2001; Sherman et al., 2016), (3) their burst-like temporal dynamics (Jones, 2016), (4) their presumed role in the flexible formation and 
A

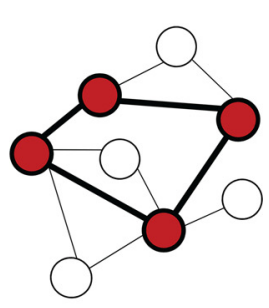

latent

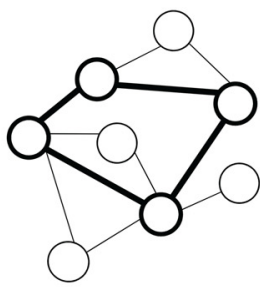

(re-)activation

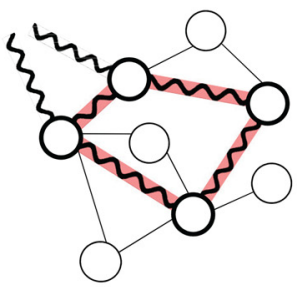

(re-)activated

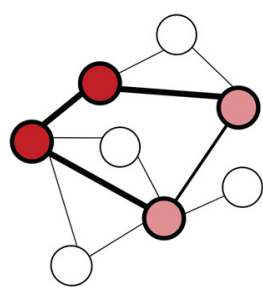

$\backsim$ long-range $\sim$ local beta

B

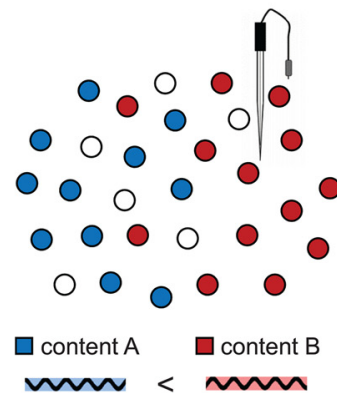

C

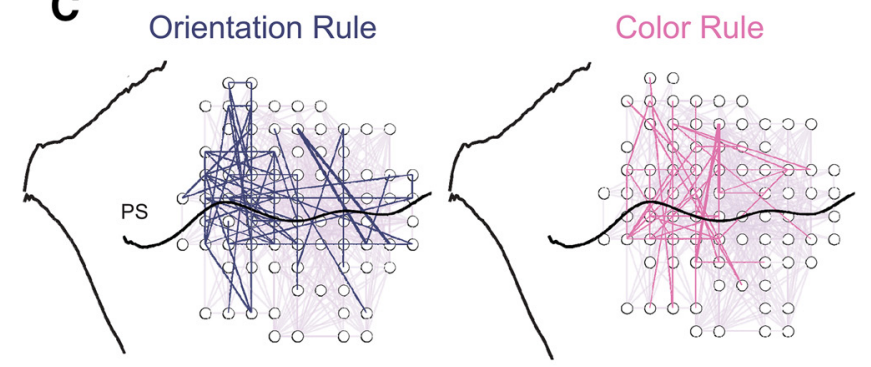

Figure 4. A framework for content-specific beta activity. A, Content-specific beta-synchronization as endogenously driven transition from latent to active cortical representation. Left, Active cortical representations (e.g., of currently perceived, task-relevant information) are characterized by spiking activity (symbolized in red) in content-specific neuronal ensembles. Second from left, In the absence of perceptual input and/or attentional prioritization, information can be retained in latent memory representations, without spiking activity in the content-specific ensemble, e.g., in patterns of synaptic weights. Second from right, Endogenously driven (re)activation of a content-coding ensemble is characterized by a brief period of beta-synchronization, involving both local and long-range (top-down) interactions (see text for details). Right, (Re)activated content representations may again be characterized by spiking ensemble activity, similar (but not necessarily exactly identical) to representations of just perceived information (compare with left). $\boldsymbol{B}$, Local beta activity appears content specific when population-level recordings register the synchronization of individual subpopulations (symbolized in blue and red) with differential sensitivity (e.g., red $>$ blue, by spatial proximity to recording site). $\boldsymbol{C}$, Transient network-level beta coherence in monkey PFC during application of different task rules (Fig. $2 F$, dashed rectangle). Adapted with permission from Buschman et al. (2012). Reprinted with permission from Elsevier.

manipulation of functional cell assemblies (Roopun et al., 2008; Kopell et al., 2011), and (5) their capacity to modulate impact of neuronal firing (Buzsáki and Draguhn, 2004; Wang, 2010). While several of these characteristics may also apply to other rhythms, the combination of all these aspects appears unique to beta.

Mechanistically, the association of endogenously driven ensemble activation with beta oscillations is in line with models of beta generation that rely on integration of concurrent inputs along the proximal and distal locations of the apical dendrites of pyramidal cells (Jones et al., 2009; Sherman et al., 2016). This integration includes both feedforward (lemniscal thalamic) input via the granular layer, and, critically, feedback (higher-order cortical and/or nonlemniscal thalamic) drives to the supragranular layers (essential for beta emergence in the model), permitting topdown driven synchronization of a cell assembly, mitigated via cortico-(thalamo)cortical drives. Furthermore, based on models that rely on beta-rate spiking-interactions within local cortical circuits (Kopell et al., 2011), it has been argued that beta-synchronized ensembles are less susceptible to competition (unlike PING/gamma networks). In the present context, this property of beta might permit endogenous content activation to operate in a "protected" oscillatory regime that is relatively robust to distractor interference, e.g., from concurrent sensory inputs.

We may further speculate that beta is an ideal "transit" band for endogenously driven (re)activation, bridging the frequency space between alpha, which is commonly associated with top-down inhibition (Klimesch et al., 2007; Haegens et al., 2011a), and gamma, which is positively linked to population spiking (Whittingstall and Logothetis, 2009). Relatedly, previous modeling work (Lundqvist et al., 2010; Lundqvist et al., 2011) has characterized (WM-) reactivation as a transition from a low-frequency (alpha/beta) oscillatory regime (associated with a noncoding ground or "default" state) to a higher frequency/ gamma regime (associated with active stimulus coding), similar to our conceptualization of latent and (re)activated representations (Fig. $4 A$, second and fourth panels). Superficially, the association of beta with a default state (Lundqvist et al., 2016; see also Engel and Fries, 2010) appears inconsistent with a role in content (re)activation. However, the two perspectives can be reconciled when considering that content specificity (in terms of experiment-related information; which might be dissociable from less specific, ongoing beta rhythmicity, see Future perspectives below) emerges only during the critical transition between representational states (Fig. 4A, third panel). 
Our proposal captures various hallmarks of contentspecific beta activity in the domains of WM and decision making. First, under this framework, content-specific beta episodes are expected to be relatively short lived (see also Jones, 2016; Sherman et al., 2016), since they would reflect neither latent nor active representations per se, but only a (presumably brief) transition period between the two (Fig. 4A). Consistently, content-specific beta modulations in WM tasks are typically observed in circumscribed time windows, in which participants should bring back past information into the focus of attention (Spitzer and Blankenburg, 2011; Spitzer et al., 2014b; Wimmer et al., 2016). Similarly, beta-oscillatory representations of task rules in monkey PFC (Fig. 4C) were short lived (Fig. $2 F)$ and appeared only while a stimulus was to be evaluated according to the current rule (Buschman et al., 2012). Notably, in the Buschman et al., study, rules were only switched between blocks of trials, likely leading to a (latent) memory of the current rule that persisted across trials. A representation of such memory in beta-synchrony was indeed absent throughout large portions of the trial, and emerged only shortly before the to-be-evaluated stimulus, as if the current rule was endogenously (re)activated for task-oriented processing. Before and after this brief episode, prefrontal firing rates, but not beta-synchrony, encoded just-presented cues, consistent with our differentiation of purely endogenous (re)activation processes in the beta-band from active neuronal representations per se (Fig. 4A).

In a similar vein, the proposed framework can explain findings of content-specific beta activity during categorization and decision making, in dissociation from traditional indices of motor preparation. In categorization tasks, subjects are asked to select one of two (or more) internalized prototype concepts, which in our framework entails the endogenous activation of a stored content representation. Indeed, category-selective beta-synchronization during stimulus categorization was found only after extensive category learning (Antzoulatos and Miller, 2014,2016 ), corroborating the idea that beta is especially involved in reactivating cortical representations. Likewise, modulations of beta activity according to categorical decision outcomes, such as in the vibrotactile frequency comparison tasks described earlier, can be understood in terms of endogenously activating an abstract concept representation, e.g., "higher" (f2 > f1) or lower ("f2 <f1"). Indeed, on any given trial in the above tasks, the concepts or categories in question may coexist in form of latent representations, one of which will be activated at the time of choice, as reflected in content-specific beta activity.

Our framework is further consistent with a nontrivial relationship between beta oscillations and spiking activity (Whittingstall and Logothetis, 2009; Rule et al., 2017). Conceiving of content-specific beta activity as a transition period (Fig. 4A), temporal correlations with spike firing can be weakly negative or positive, depending on how strongly beta episodes overlap in time with (still) dormant or (already) activated representations. Furthermore, rather than in- or decreases of net firing rates in a given area, we assume a (content-specific) distribution of neuronal firing within and/or between functional ensembles. This idea is in line with the spatio-temporal coincidence of local beta modulations with a shifting of firing rates between oppositely tuned cell populations (Romo et al., 1999; Hernández et al., 2002; Barak et al., 2010; Spitzer et al., 2010; Haegens et al., 2011b; Hussar and Pasternak, 2012; Wimmer et al., 2016). In these contexts, beta activity may appear content specific to the extent that population-level recordings (such as M/EEG or LFP) register the oscillatory signatures of individual subpopulations with different sensitivity (Fig. 4B). As a corollary of this view, the sign of content-dependent beta modulations (e.g., whether local beta activity in- or decreases for a given content) might be noninformative and dependent on the particular recording setting. However, the precise relation between beta oscillations and spiking ensemble activity remains speculative and awaits further investigation.

Based on the available findings across primate species, endogenous content (re)activation can include modulations of beta activity both locally and in terms of longrange synchronization between distant regions (Fig. 1B). Modulations of local beta power have mostly been observed for low-dimensional information, such as scalar stimulus attributes (Spitzer et al., 2010; Haegens et al., 2011b; Wimmer et al., 2016). Higher-dimensional contents, such as object identity or task rules, have been associated with sophisticated patterns of beta-synchronization between multiple recording sites, potentially reflecting the activation of more distributed cortical representations (Buschman et al., 2012; Salazar et al., 2012; Antzoulatos and Miller, 2016). In all of these cases, beta seems to provide a flexible scaffolding that sets up functional neuronal ensembles through temporary synchronization of content-coding cell populations. The demand for flexibility in ensemble formation may be particularly high in regions with "mixed selectivity" cells (Rigotti et al., 2013), such as the prefrontal and parietal cortices, where single neurons respond to a multiplicity of task variables (for review, see Fusi et al., 2016). It might be especially in communication within and with these regions that frequency-specific synchronization finesses the active representation of internally stored information alongside current input, in potentially overlapping functional networks.

\section{Future perspectives}

An open question remains whether transient content specificity of beta emerges from a modification of ongoing beta rhythmicity (cf. Engel and Fries, 2010; Lundqvist et al., 2016), or whether the two reflect functionally dissociable phenomena in overlapping frequency ranges. It is possible that the beta-band encompasses several rhythms, including a potentially "inhibitory" rhythm that is functionally more similar to alpha and which seems especially prevalent in somatomotor context (for review, see Kilavik et al., 2013). Indeed, the possibility that beta is not a unitary phenomenon but covers several roles may help to reconcile seemingly disparate observations, such as WM-load-related beta-power increases in some studies (Deiber et al., 2007; Kornblith et al., 2016), but decreases 
in others (Siegel et al., 2009; Lundqvist et al., 2011). Relatedly, several authors divide the beta-band into a lower $(<20 \mathrm{~Hz})$ and a higher $(>20 \mathrm{~Hz})$ subrange (Roopun et al., 2006; Kopell et al., 2011), with potentially distinct functional roles (see Introduction). In the literature reviewed here, however, we found only a weak, if any, tendency for content-specific effects (Fig. 1A, right) to occur in a higher beta frequency than overall, task-related modulations (Fig. $1 A$, left), with considerable variability across experiments, leaving the question of potentially distinct beta rhythms (and the determinants of their precise frequencies across cortical areas) to future targeted study.

A more general open question is the very nature of latent representations that are amenable to beta-mediated reactivation. As one possibility, content-specific beta activity might reflect a direct drive to reactivate activity-silent (e.g., synaptic) representations, as schematically illustrated in Figure $4 A$. In an alternative scenario, dormant memory representations are kept "silent" by actively inhibitory mechanisms, for instance, by content-matching "inhibitory engrams" (Ramaswami, 2014; Barron et al., 2017). Under this view, cortical reactivation may result from a release from inhibition, by suppression of inhibitory engrams, a scenario in which beta-mediated reactivation might indeed operate via inhibitory processes ("inhibition of inhibition"; Pfeffer et al., 2013). A related issue is the extent to which beta-mediated reactivation relies on the contents or concepts in question being familiar and consolidated in long(er)-term memory (which we assumed to be the case in most of the above reviewed studies). It remains to be shown empirically whether content-specific synchronization plays a role also in reactivating representations of entirely novel, just encountered information, a silent memory of which might persist only in transient patterns of short-term synaptic plasticity (Mongillo et al., 2008; Stokes, 2015).

Lastly, a key question for future work is how burst-like, transient beta events are temporally organized. One possibility is that temporal context is provided by other (lower) frequency rhythms that modulate beta via crossfrequency interactions. For instance, $\delta$ oscillations (1-3 $\mathrm{Hz}$ ) are thought to tap into the temporal structure of behaviorally relevant events (reviewed in Merchant et al., 2015; cf. Lakatos et al., 2008; Schroeder and Lakatos, 2009), with faster oscillations "nested" in these slower rhythms. Such interactions might manifest in phase-amplitude coupling, where the phase of $\delta$ provides "windows-of-opportunity" for beta to burst. Indeed, there are indications that beta power can be modulated by $\delta$ oscillations in the context of WM (Siegel et al., 2009) and temporal prediction (Arnal et al., 2015; Herrmann et al., 2016). Such temporal structuring could be implemented via corticothalamocortical, and/or cortico-basal ganglia loops (cf. Merchant et al., 2015). For example, beta could be timed by bursting thalamic inputs (cf. Sherman et al., 2016), which in turn could be gated via the basal ganglia. Albeit speculative, these ideas are in line with studies showing that beta oscillations in the basal ganglia are associated with interval timing (Bartolo et al., 2014), providing promising avenues for future research.

\section{Conclusion}

To summarize, we propose that content-specific betasynchronization provides a mechanism for the formation of functional neuronal ensembles during endogenous (re)activation of cortical representations. This framework is in line with the emerging view that beta facilitates networklevel communication (Kopell et al., 2000; Varela et al., 2001; Siegel et al., 2011) and specifically endogenous, top-down driven interactions (Engel and Fries, 2010; Wang, 2010; Arnal and Giraud, 2012; Bastos et al., 2012; Sherman et al., 2016). However, beyond a static role in maintaining the status quo (cf. Engel and Fries, 2010), we characterize content-specific beta-synchronization as a dynamic and highly flexible mechanism, one that can "wake up" (see also Fries, 2015), rather than merely preserve, an endogenous cognitive set. This proposal accommodates accumulating findings in animals and humans and outlines a functional role for beta that may fit its "burst-like" temporal characteristics (Jones, 2016). An intriguing question for future research is whether and how the beta-band dynamics discussed here interact with sensorimotor rhythms when (re)activated content representations are translated into concrete action plans.

\section{References}

Alavash M, Daube C, Wöstmann M, Brandmeyer A, Obleser J (2017) Large-scale network dynamics of beta-band oscillations underlie auditory perceptual decision-making. Net Neurosci 1:166-191. CrossRef

Antzoulatos EG, Miller EK (2014) Increases in functional connectivity between prefrontal cortex and striatum during category learning. Neuron 83:216-225. CrossRef Medline

Antzoulatos EG, Miller EK (2016) Synchronous beta rhythms of frontoparietal networks support only behaviorally relevant representations. eLife 5:e17822. CrossRef

Arnal LH, Giraud AL (2012) Cortical oscillations and sensory predictions. Trends Cogn Sci 16:1-9.

Arnal LH, Doelling KB, Poeppel D (2015) Delta-beta coupled oscillations underlie temporal prediction accuracy. Cereb Cortex 25: 3077-3085. CrossRef

Axmacher N, Schmitz DP, Wagner T, Elger CE, Fell J (2008) Interactions between medial temporal lobe, prefrontal cortex, and inferior temporal regions during visual working memory: a combined intracranial eeg and functional magnetic resonance imaging study. $J$ Neurosci 28:7304-7312. CrossRef Medline

Babiloni C, Babiloni F, Carducci F, Cincotti F, Vecchio F, Cola B, Rossi S, Miniussi C, Rossini PM (2004) Functional frontoparietal connectivity during short-term memory as revealed by highresolution EEG coherence analysis. Behav Neurosci 118:687-697. CrossRef Medline

Barak O, Tsodyks M, Romo R (2010) Neuronal population coding of parametric working memory. J Neurosci 30:9424-9430. CrossRef Medline

Barron HC, Vogels TP, Behrens TE, Ramaswami M (2017) Inhibitory engrams in perception and memory. Proc Natl Acad Sci USA 114:6666-6674.

Bartolo R, Prado L, Merchant H (2014) Information processing in the primate basal ganglia during sensory-guided and internally driven rhythmic tapping. J Neurosci 34:3910-3923. CrossRef Medline

Bastos AM, Usrey WM, Adams RA, Mangun GR, Fries P, Friston KJ (2012) Canonical microcircuits for predictive coding. Neuron 76: 695-711. CrossRef Medline 
Bastos AM, Vezoli J, Bosman CA, Schoffelen J-M, Oostenveld R, Dowdall JR, De Weerd P, Kennedy H, Fries P (2015) Visual areas exert feedforward and feedback influences through distinct frequency channels. Neuron 85:390-401. CrossRef Medline

Bauer M, Oostenveld R, Peeters M, Fries P (2006) Tactile spatial attention enhances gamma-band activity in somatosensory cortex and reduces low-frequency activity in parieto-occipital areas. $J$ Neurosci 26:490-501. CrossRef Medline

Benchenane K, Tiesinga PH, Battaglia FP (2011) Oscillations in the prefrontal cortex: a gateway to memory and attention. Curr Opin Neurobiol 21:475-485. CrossRef Medline

Bidet-Caulet A, Barbe P-G, Roux S, Viswanath $H$, Barthélémy $C$, Bruneau N, Knight RT, Bonnet-Brilhault F (2012) Dynamics of anticipatory mechanisms during predictive context processing. Eur J Neurosci 36:2996-3004. CrossRef Medline

Bishop GH (1932) Cyclic changes in excitability of the optic pathway of the rabbit. Am J Physiol 103:213-224.

Buschman TJ, Miller EK (2007) Top-down versus bottom-up control of attention in the prefrontal and posterior parietal cortices. Science 315:1860-1862. CrossRef Medline

Buschman TJ, Denovellis EL, Diogo C, Bullock D, Miller EK (2012) Synchronous oscillatory neural ensembles for rules in the prefrontal cortex. Neuron 76:838-846. CrossRef Medline

Buzsáki G, Draguhn A (2004) Neuronal oscillations in cortical networks. Science 304:1926-1929. CrossRef Medline

Chen Y, Huang X (2016) Modulation of alpha and beta oscillations during an n-back task with varying temporal memory load. Front Psychol 6:2031. CrossRef

Christophel TB, Klink PC, Spitzer B, Roelfsema PR, Haynes J-D (2017) The distributed nature of working memory. Trends Cogn Sci 21:111-124. CrossRef Medline

Crone NE, Miglioretti DL, Gordon B, Sieracki JM, Wilson MT, Uematsu S, Lesser RP (1998) Functional mapping of human sensorimotor cortex with electrocorticographic spectral analysis. I. Alpha and beta event-related desynchronization. Brain 121:22712299. CrossRef

Deiber M-P, Missonnier P, Bertrand O, Gold G, Fazio-Costa L, Ibañez V, Giannakopoulos P (2007) Distinction between perceptual and attentional processing in working memory tasks: a study of phase-locked and induced oscillatory brain dynamics. J Cogn Neurosci 19:158-172. CrossRef

Dipoppa M, Gutkin BS (2013) Flexible frequency control of cortical oscillations enables computations required for working memory. Proc Natl Acad Sci USA 110:12828-12833.

Donner TH, Siegel M, Oostenveld R, Fries P, Bauer M, Engel AK (2007) Population activity in the human dorsal pathway predicts the accuracy of visual motion detection. J Neurophysiol 98:345359. CrossRef Medline

Donner TH, Siegel M, Fries P, Engel AK (2009) Buildup of choicepredictive activity in human motor cortex during perceptual decision making. Curr Biol 19:1581-1585. CrossRef

Dotson NM, Salazar RF, Gray CM (2014) Frontoparietal correlation dynamics reveal interplay between integration and segregation during visual working memory. J Neurosci 34:13600-13613. CrossRef Medline

Engel AK, Fries $P$ (2010) Beta-band oscillations - signalling the status quo? Curr Opin Neurobiol 20:156-165. CrossRef Medline

Fell J, Axmacher N (2011) The role of phase synchronization in memory processes. Nat Rev Neurosci 12:105-118. CrossRef Medline

Fries P (2005) A mechanism for cognitive dynamics: neuronal communication through neuronal coherence. Trends Cogn Sci 9:474480. CrossRef Medline

Fries P (2015) Rhythms for cognition: communication through coherence. Neuron 88:220-235. CrossRef Medline

Fusi S, Miller EK, Rigotti M (2016) Why neurons mix: high dimensionality for higher cognition. Curr Opin Neurobiol 37:66-74. CrossRef Medline

Gould IC, Nobre AC, Wyart V, Rushworth MFS (2012) Effects of decision variables and intraparietal stimulation on sensorimotor oscillatory activity in the human brain. J Neurosci $32: 1-14$. CrossRef

Haegens S, Nácher V, Luna R, Romo R, Jensen O (2011a) alphaOscillations in the monkey sensorimotor network influence discrimination performance by rhythmical inhibition of neuronal spiking. Proc Natl Acad Sci USA 108:19377-19382.

Haegens S, Nácher V, Hernández A, Luna R, Jensen O, Romo R (2011b) Beta oscillations in the monkey sensorimotor network reflect somatosensory decision making. Proc Natl Acad Sci USA 108:10708-10713.

Haegens S, Luther L, Jensen O (2012) Somatosensory anticipatory alpha activity increases to suppress distracting input. J Cogn Neurosci 24:677-685. CrossRef Medline

HansImayr S, Spitzer B, Bäuml KH (2009) Brain oscillations dissociate between semantic and nonsemantic encoding of episodic memories. Cereb Cortex 19:1631-1640. CrossRef

HansImayr S, Volberg G, Wimber M, Raabe M, Greenlee MW, Bäuml K-HT (2011) The relationship between brain oscillations and BOLD signal during memory formation: a combined EEG-fMRI study. J Neurosci 31:15674-15680. CrossRef

Hanslmayr S, Staresina BP, Bowman H (2016) Oscillations and episodic memory: addressing the synchronization/desynchronization conundrum. Trends Neurosci 39:16-25. CrossRef Medline

Hari R, Salmelin R (1997) Human cortical oscillations: a neuromagnetic view through the skull. Trends Neurosci 20:44-49. CrossRef Medline

Harrison SA, Tong F (2009) Decoding reveals the contents of visual working memory in early visual areas. Nature 458:632-635. CrossRef Medline

Hawellek DJ, Wong YT, Pesaran B (2016) Temporal coding of reward-guided choice in the posterior parietal cortex. Proc Natl Acad Sci USA 113:13492-13497. CrossRef

Hebb DO (1949) The organization of behavior: a neuropsychological theory. New York: Wiley.

Herding J, Spitzer B, Blankenburg F (2016) Upper beta band oscillations in human premotor cortex encode subjective choices in a vibrotactile comparison task. J Cogn Neurosci 28:668-679. CrossRef

Herding J, Ludwig S, Blankenburg F (2017) Response-modalityspecific encoding of human choices in upper beta-band oscillations during vibrotactile comparisons. Front Hum Neurosci 11:118. CrossRef

Hernández A, Zainos A, Romo R (2002) Temporal evolution of a decision-making process in medial premotor cortex. Neuron 33: 959-972. Medline

Hernández A, Nácher V, Luna R, Zainos A, Lemus L, Alvarez M, Vázquez Y, Camarillo L, Romo R (2010) Decoding a perceptual decision process across cortex. Neuron 66:300-314. CrossRef Medline

Herrmann B, Henry MJ, Haegens S, Obleser J (2016) Temporal expectations and neural amplitude fluctuations in auditory cortex interactively influence perception. Neurolmage 124:487-497. CrossRef Medline

Holgado AJN, Terry JR, Bogacz R (2010) Conditions for the generation of beta oscillations in the subthalamic nucleus-globus pallidus network. J Neurosci 30:12340-12352. CrossRef

Honkanen R, Rouhinen S, Wang SH, Palva JM, Palva S (2015) Gamma oscillations underlie the maintenance of feature-specific information and the contents of visual working memory. Cereb Cortex 25:3788-3801. CrossRef Medline

Hussar CR, Pasternak T (2012) Memory-guided sensory comparisons in the prefrontal cortex: contribution of putative pyramidal cells and interneurons. J Neurosci 32:2747-2761. CrossRef Medline

Jacob SN, Nieder A (2014) Complementary roles for primate frontal and parietal cortex in guarding working memory from distractor stimuli. Neuron 83:226-237. CrossRef Medline

Jenkinson N, Brown P (2011) New insights into the relationship between dopamine, beta oscillations and motor function. Trends Neurosci 34:611-618. CrossRef Medline 
Jensen O, Goel P, Kopell N, Pohja M, Hari R, Ermentrout B (2005) On the human sensorimotor-cortex beta rhythm: sources and modeling. Neurolmage 26:347-355. CrossRef Medline

Jensen O, Mazaheri A (2010) Shaping functional architecture by oscillatory alpha activity: gating by inhibition. Front Hum Neurosci 4:186. CrossRef Medline

Jha A, Nachev P, Barnes G, Husain M, Brown P, Litvak V (2015) The frontal control of stopping. Cereb Cortex 25:4392-4406. CrossRef Medline

Johnson MK (1992) MEM: mechanisms of recollection. J Cogn Neurosci 4:268-280. CrossRef Medline

Jones SR (2016) When brain rhythms aren't 'rhythmic': implication for their mechanisms and meaning. Curr Opin Neurobiol 40:72-80. CrossRef Medline

Jones SR, Pritchett DL, Stufflebeam SM, Hämäläinen M, Moore CI (2007) Neural correlates of tactile detection: a combined magnetoencephalography and biophysically based computational modeling study. J Neurosci 27:10751-10764. CrossRef Medline

Jones SR, Pritchett DL, Sikora MA, Stufflebeam SM, Hämäläinen M, Moore $\mathrm{Cl}$ (2009) Quantitative analysis and biophysically realistic neural modeling of the MEG mu rhythm: rhythmogenesis and modulation of sensory-evoked responses. J Neurophysiol 102: 3554-3572. CrossRef Medline

Jones SR, Kerr CE, Wan Q, Pritchett DL, Hämäläinen M, Moore Cl (2010) Cued spatial attention drives functionally relevant modulation of the mu rhythm in primary somatosensory cortex. J Neurosci 30:13760-13765. CrossRef Medline

Jonides J, Lewis RL, Nee DE, Lustig CA, Berman MG, Moore KS (2008) The mind and brain of short-term memory. Annu Rev Psychol 59:193-224. CrossRef Medline

Kaiser J, Lennert T, Lutzenberger W (2007) Dynamics of oscillatory activity during auditory decision making. Cereb Cortex 17:22582267. CrossRef Medline

Kilavik BE, Zaepffel M, Brovelli A, MacKay WA, Riehle A (2013) The ups and downs of beta oscillations in sensorimotor cortex. Exp Neurol 245:15-26. CrossRef Medline

Klimesch W, Sauseng P, HansImayr S (2007) EEG alpha oscillations: the inhibition-timing hypothesis. Brain Res Rev 53:63-88. CrossRef Medline

Kloosterman NA, Meindertsma T, Hillebrand A, van Dijk BW, Lamme VAF, Donner TH (2015) Top-down modulation in human visual cortex predicts the stability of a perceptual illusion. J Neurophysiol 113:1063-1076. CrossRef

Kopell N, Ermentrout GB, Whittington MA, Traub RD (2000) Gamma rhythms and beta rhythms have different synchronization properties. Proc Natl Acad Sci USA 97:1867-1872. CrossRef

Kopell N, Whittington MA, Kramer MA (2011) Neuronal assembly dynamics in the beta1 frequency range permits short-term memory. Proc Natl Acad Sci USA 108:3779-3784. CrossRef

Kornblith S, Buschman TJ, Miller EK (2016) Stimulus load and oscillatory activity in higher cortex. Cereb Cortex 26:3772-3784. CrossRef Medline

Kramer MA, Roopun AK, Carracedo LM, Traub RD, Whittington MA, Kopell NJ (2008) Rhythm generation through period concatenation in rat somatosensory cortex. PLoS Comput Biol 4:e1000169. CrossRef Medline

Kubanek J, Snyder LH, Brunton BW, Brody CD, Schalk G (2013) A low-frequency oscillatory neural signal in humans encodes a developing decision variable. Neurolmage 83:795-808. CrossRef Medline

Kubota K, Iwamoto T, Suzuki H (1974) Visuokinetic activities of primate prefrontal neurons during delayed-response performance. J Neurophysiol 37:1197-1212. Medline

Lakatos P, Karmos G, Mehta AD, Ulbert I, Schroeder CE (2008) Entrainment of neuronal oscillations as a mechanism of attentional selection. Science 320:110-113. CrossRef Medline

Lara AH, Wallis JD (2014) Executive control processes underlying multi-item working memory. Nat Neurosci 17:876-883. CrossRef Medline
Lee JH, Whittington MA, Kopell NJ (2013) Top-down beta rhythms support selective attention via interlaminar interaction: a model. PLoS Comput Biol 9:e1003164-e1003123. CrossRef Medline

Lewis CM, Bosman CA, Brunet NM, Lima B, Roberts MJ, Womelsdorf T, Weerd P, Neuenschwander S, Singer W, Fries P (2016) Two frequency bands contain the most stimulus-related information in visual cortex. bioRxiv 049718

Liebe S, Hoerzer GM, Logothetis NK, Rainer G (2012) Theta coupling between V4 and prefrontal cortex predicts visual short-term memory performance. Nat Neurosci 15:456-462. CrossRef Medline

Lisman JE, Jensen $O$ (2013) The $\theta$-gamma neural code. Neuron 77:1002-1016. CrossRef Medline

Ludwig S, Spitzer B, Jacobs AM, Sekutowicz M, Sterzer P, Blankenburg F (2016) Spectral EEG abnormalities during vibrotactile encoding and quantitative working memory processing in schizophrenia. Neurolmage 11:578-587. CrossRef Medline

Lundqvist M, Compte A, Lansner A (2010) Bistable, irregular firing and population oscillations in a modular attractor memory network. PLoS Comput Biol 6:e1000803. CrossRef

Lundqvist M, Herman P, Lansner A (2011) Theta and gamma power increases and alpha/beta power decreases with memory load in an attractor network model. J Cogn Neurosci 23:3008-3020. CrossRef

Lundqvist M, Rose J, Herman P, Brincat SL, Buschman TJ, Miller EK (2016) Gamma and beta bursts underlie working memory. Neuron 90:152-164. CrossRef Medline

Marco-Pallarés J, Münte TF, Rodríguez-Fornells A (2015) The role of high-frequency oscillatory activity in reward processing and learning. Neurosci Biobehav Rev 49:1-7. CrossRef Medline

McCarthy MM, Moore-Kochlacs C, Gu X, Boyden ES, Han X, Kopell $N$ (2011) Striatal origin of the pathologic beta oscillations in Parkinson's disease. Proc Natl Acad Sci USA 108:11620-11625. CrossRef Medline

Mendoza-Halliday D, Torres S, Martinez-Trujillo JC (2014) Sharp emergence of feature-selective sustained activity along the dorsal visual pathway. Nat Neurosci 17:1255-1262. CrossRef Medline

Merchant H, Grahn J, Trainor L, Rohrmeier M, Fitch WT (2015) Finding the beat: a neural perspective across humans and nonhuman primates. Philos Trans R Soc Lond B Biol Sci 370: 20140093. CrossRef

Michalareas G, Vezoli J, van Pelt S, Schoffelen J-M, Kennedy $H$, Fries $P(2016)$ Alpha-beta and gamma rhythms subserve feedback and feedforward influences among human visual cortical areas. Neuron 89:384-397. CrossRef Medline

Michels L, Bucher K, Lüchinger R, Klaver P, Martin E, Jeanmonod D, Brandeis D (2010) Simultaneous EEG-fMRI during a working memory task: modulations in low and high frequency bands. PLoS One 5:e10298. CrossRef Medline

Miller EK, Erickson CA, Desimone R (1996) Neural mechanisms of visual working memory in prefrontal cortex of the macaque. $\mathrm{J}$ Neurosci 16:5154-5167. Medline

Mongillo G, Barak O, Tsodyks M (2008) Synaptic theory of working memory. Science 319:1543-1546. CrossRef Medline

Mountcastle VB, Talbot WH, Darian-Smith I, Kornhuber HH (1967) Neural basis of the sense of flutter-vibration. Science 155:597600. Medline

Murthy VN, Fetz EE (1992) Coherent 25- to $35-\mathrm{Hz}$ oscillations in the sensorimotor cortex of awake behaving monkeys. Proc Natl Acad Sci USA 89:5670-5674. Medline

Myers NE, Rohenkohl G, Wyart V, Woolrich MW, Nobre AC, Stokes MG (2015) Testing sensory evidence against mnemonic templates. eLife 4:e09000. CrossRef Medline

Neuper C, Pfurtscheller G (2001) Event-related dynamics of cortical rhythms: frequency-specific features and functional correlates. Int J Psychophysiol 43:41-58. Medline

Nieder A (2012) Supramodal numerosity selectivity of neurons in primate prefrontal and posterior parietal cortices. Proc Natl Acad Sci USA 109:11860-11865. CrossRef 
O'Connell RG, Dockree PM, Kelly SP (2012) A supramodal accumulation-to-bound signal that determines perceptual decisions in humans. Nat Neurosci 15:1729-1735.

Oberauer K (2002) Access to information in working memory: exploring the focus of attention. J Exp Psychol Learn Mem Cogn 28: 411-421. Medline

Palmigiano A, Geisel T, Wolf F, Battaglia D (2017) Flexible information routing by transient synchrony. Nat Neurosci 20:1014-1022. CrossRef Medline

Palva S, Kulashekhar S, Hämäläinen M, Palva JM (2011) Localization of cortical phase and amplitude dynamics during visual working memory encoding and retention. J Neurosci 31:5013-5025. CrossRef Medline

Pesaran B, Nelson MJ, Andersen RA (2008) Free choice activates a decision circuit between frontal and parietal cortex. Nature 453: 406-409. CrossRef Medline

Pesaran B, Pezaris JS, Sahani M, Mitra PP, Andersen RA (2002) Temporal structure in neuronal activity during working memory in macaque parietal cortex. Nat Neurosci 5:805-811. CrossRef Medline

Pfeffer CK, Xue M, He M, Huang ZJ, Scanziani M (2013) Inhibition of inhibition in visual cortex: the logic of connections between molecularly distinct interneurons. Nat Neurosci 16:1068-1076. CrossRef Medline

Pfurtscheller G, Lopes da Silva FH (1999) Event-related EEG/MEG synchronization and desynchronization: basic principles. Clin Neurophysiol 110:1842-1857. Medline

Pfurtscheller G, Stancák A Jr, Neuper C (1996) Event-related synchronization (ERS) in the alpha band - an electrophysiological correlate of cortical idling: a review. Int J Psychophysiol 24:39-46. Medline

Piantoni G, Kline KA, Eagleman DM (2010) Beta oscillations correlate with the probability of perceiving rivalrous visual stimuli. J Vis 10:18-18. CrossRef Medline

Ramaswami M (2014) Network plasticity in adaptive filtering and behavioral habituation. Neuron 82:1216-1229. CrossRef Medline

Rigotti M, Barak O, Warden MR, Wang X-J, Daw ND, Miller EK, Fusi $S$ (2013) The importance of mixed selectivity in complex cognitive tasks. Nature 497:585-590. CrossRef Medline

Romo R, de Lafuente V (2013) Conversion of sensory signals into perceptual decisions. Prog Neurobiol 103:41-75. CrossRef Medline

Romo R, Brody CD, Hernández A, Lemus L (1999) Neuronal correlates of parametric working memory in the prefrontal cortex. Nature 399:470-473. CrossRef Medline

Romo R, Hernández A, Zainos A, Lemus L, Brody CD (2002) Neuronal correlates of decision-making in secondary somatosensory cortex. Nat Neurosci 5:1217-1225. CrossRef Medline

Roopun AK, Middleton SJ, Cunningham MO, LeBeau FEN, Bibbig A, Whittington MA, Traub RD (2006) A beta2-frequency $(20-30 \mathrm{~Hz})$ oscillation in nonsynaptic networks of somatosensory cortex. Proc Natl Acad Sci USA 103:15646-15650. CrossRef

Roopun AK, Kramer MA, Carracedo LM, Kaiser M, Davies CH, Traub RD, Kopell NJ, Whittington MA (2008) Period concatenation underlies interactions between gamma and beta rhythms in neocortex. Front Cell Neurosci 2:1. CrossRef Medline

Rose NS, LaRocque JJ, Riggall AC, Gosseries O, Starrett MJ, Meyering EE, Postle BR (2016) Reactivation of latent working memories with transcranial magnetic stimulation. Science 354:11361139. CrossRef Medline

Roux F, Uhlhaas PJ (2014) Working memory and neural oscillations: alpha-gamma versus $\theta$-gamma codes for distinct WM information? Trends Cogn Sci 18:16-25. CrossRef Medline

Rule ME, Vargas-Irwin CE, Donoghue JP, Truccolo W (2017) Dissociation between sustained single-neuron spiking beta-rhythmicity and transient beta-LFP oscillations in primate motor cortex. $\mathrm{J}$ Neurophysiol 117:1524-1543.

Sacchet MD, LaPlante RA, Wan Q, Pritchett DL, Lee AKC, Hamalainen M, Moore Cl, Kerr CE, Jones SR (2015) Attention drives synchronization of alpha and beta rhythms between right inferior frontal and primary sensory neocortex. J Neurosci 35:2074-2082. CrossRef

Salazar RF, Dotson NM, Bressler SL, Gray CM (2012) Contentspecific fronto-parietal synchronization during visual working memory. Science 338:1097-1100. CrossRef Medline

Sanes JN, Donoghue JP (1993) Oscillations in local field potentials of the primate motor cortex during voluntary movement. Proc Natl Acad Sci USA 90:4470-4474. CrossRef

Schmiedt JT, Maier A, Fries P, Saunders RC, Leopold DA, Schmid MC (2014) Beta oscillation dynamics in extrastriate cortex after removal of primary visual cortex. J Neurosci 34:11857-11864. CrossRef Medline

Schroeder CE, Lakatos P (2009) Low-frequency neuronal oscillations as instruments of sensory selection. Trends Neurosci 32:9-18. CrossRef Medline

Schubert R, Haufe S, Blankenburg F, Villringer A, Curio G (2009) Now you'll feel it, now you won't: EEG rhythms predict the effectiveness of perceptual masking. J Cogn Neurosci 21:2407-2419. CrossRef Medline

Sederberg PB, Gauthier LV, Terushkin V, Miller JF, Barnathan JA, Kahana MJ (2006) Oscillatory correlates of the primacy effect in episodic memory. Neurolmage 32:1422-1431. CrossRef Medline Sherman MA, Lee S, Law R, Haegens S, Thorn CA, Hämäläinen MS, Moore Cl, Jones SR (2016) Neural mechanisms of transient neocortical beta rhythms: converging evidence from humans, computational modeling, monkeys, and mice. Proc Natl Acad Sci USA 113:E4885-E4894.

Siegel M, Warden MR, Miller EK (2009) Phase-dependent neuronal coding of objects in short-term memory. Proc Natl Acad Sci USA 106:21341-21346. CrossRef

Siegel M, Engel A, Donner T (2011) Cortical network dynamics of perceptual decision-making in the human brain. Front Hum Neurosci 5:12. CrossRef

Spitzer B, Blankenburg F (2011) Stimulus-dependent EEG activity reflects internal updating of tactile working memory in humans. Proc Natl Acad Sci USA 108:8444-8449. CrossRef

Spitzer B, Blankenburg F (2012) Supramodal parametric working memory processing in humans. J Neurosci 32:3287-3295. CrossRef Medline

Spitzer B, Wacker E, Blankenburg F (2010) Oscillatory correlates of vibrotactile frequency processing in human working memory. $J$ Neurosci 30:4496-4502. CrossRef Medline

Spitzer B, Fleck S, Blankenburg F (2014a) Parametric alpha- and beta-band signatures of supramodal numerosity information in human working memory. J Neurosci 34:4293-4302.

Spitzer B, Gloel M, Schmidt TT, Blankenburg F (2014b) Working memory coding of analog stimulus properties in the human prefrontal cortex. Cereb Cortex 24:2229-2236.

Spitzer B, Hanslmayr S, Opitz B, Mecklinger A, Bäuml K-H (2009) Oscillatory correlates of retrieval-induced forgetting in recognition memory. J Cogn Neurosci 21:976-990. CrossRef Medline

Sprague TC, Ester EF, Serences JT (2016) Restoring latent visual working memory representations in human cortex. Neuron 91: 694-707. CrossRef Medline

Stanley DA, Roy JE, Aoi MC, Kopell NJ (2016) Low-beta oscillations turn up the gain during category judgments. Cereb Cortex. CrossRef

Stokes MG (2015) 'Activity-silent' working memory in prefrontal cortex: a dynamic coding framework. Trends Cogn Sci 19:394-405. CrossRef

Tallon-Baudry C, Bertrand O, Peronnet F, Pernier J (1998) Induced gamma-band activity during the delay of a visual short-term memory task in humans. J Neurosci 18:4244-4254. Medline

Tallon-Baudry C, Bertrand O, Fischer C (2001) Oscillatory synchrony between human extrastriate areas during visual short-term memory maintenance. J Neurosci 21:RC177. Medline

Tallon-Baudry C, Mandon S, Freiwald WA, Kreiter AK (2004) Oscillatory synchrony in the monkey temporal lobe correlates with 
performance in a visual short-term memory task. Cereb Cortex 14:713-720. CrossRef

Twomey DM, Kelly SP, O'Connell RG (2016) Abstract and effectorselective decision signals exhibit qualitatively distinct dynamics before delayed perceptual reports. J Neurosci 36:7346-7352. CrossRef

Van Ede F, Jensen O, Maris E (2010) Tactile expectation modulates pre-stimulus beta-band oscillations in human sensorimotor cortex. Neurolmage 51:867-876. CrossRef Medline

Van Ede F, de Lange F, Jensen O, Maris E (2011) Orienting attention to an upcoming tactile event involves a spatially and temporally specific modulation of sensorimotor alpha- and beta-band oscillations. J Neurosci 31:2016-2024. CrossRef

Varela F, Lachaux J-P, Rodriguez E, Martinerie J (2001) The brainweb: phase synchronization and large-scale integration. Nat Rev Neurosci 2:229-239. CrossRef Medline

Vergara J, Rivera N, Rossi-Pool R, Romo R (2016) A neural parametric code for storing information of more than one sensory modality in working memory. Neuron 89:54-62. CrossRef Medline

Wang X-J (2010) Neurophysiological and computational principles of cortical rhythms in cognition. Physiol Rev 90:1195-1268. CrossRef Medline

Warden MR, Miller EK (2007) The representation of multiple objects in prefrontal neuronal delay activity. Cereb Cortex 17 [Suppl 1]: i41-i50. CrossRef
Watanabe K, Funahashi S (2014) Neural mechanisms of dual-task interference and cognitive capacity limitation in the prefrontal cortex. Nat Neurosci 17:601-611. CrossRef Medline

Weiss S, Mueller HM (2012) "Too many betas do not spoil the broth": the role of beta brain oscillations in language processing. Front Psychol 3:201. CrossRef Medline

Whittingstall K, Logothetis NK (2009) Frequency-band coupling in surface EEG reflects spiking activity in monkey visual cortex. Neuron 64:281-289. CrossRef Medline

Wimmer K, Ramon M, Pasternak T, Compte A (2016) Transitions between multiband oscillatory patterns characterize memoryguided perceptual decisions in prefrontal circuits. J Neurosci 36: 489-505. CrossRef Medline

Wong YT, Fabiszak MM, Novikov Y, Daw ND, Pesaran B (2016) Coherent neuronal ensembles are rapidly recruited when making a lookreach decision. Nat Neurosci 19:327-334. CrossRef

Wyart V, de Gardelle V, Scholl J, Summerfield C (2012) Rhythmic fluctuations in evidence accumulation during decision making in the human brain. Neuron 76:847-858. CrossRef Medline

Wyart V, Myers NE, Summerfield C (2015) Neural mechanisms of human perceptual choice under focused and divided attention. $J$ Neurosci 35:3485-3498. CrossRef Medline

Zhang Y, Chen Y, Bressler SL, Ding M (2008) Response preparation and inhibition: the role of the cortical sensorimotor beta rhythm. Neuroscience 156:238-246. CrossRef Medline 